\title{
Pancreatic actinomycosis presenting as pancreatic mass and diagnosed with endoscopic ultrasound fine needle aspiration (EUS-FNA)
}

We present the case of a 66-year-old man with a 4-month history of abdominal pain poorly responsive to opiate analgesics and with occasional fever. Prior to attending our unit, he had undergone basic studies and computed tomography (CT) at another hospital. The contrast-enhanced pancreatic protocol CT demonstrated a solid mass $(16 \times 18 \mathrm{~mm})$ at the upper end of the body of the pancreas. The patient was referred to our endoscopy unit, and on endoscopic ultrasound (EUS) a hypoechoic round mass was found. A fine needle aspiration (FNA) biopsy provided an adequate sample for histological examination ( Video 1). There were no immediate complications following the biopsy. Histopathological analysis demonstrated chronic fibrosis ( Fig. $\mathbf{1}$ ) and a diagnosis of actinomycosis was made. Clinically, the patient responded well to a 6-month course of antibiotics (penicillin). A repeat EUS at 6 months showed partial resolution of the pancreatic mass, and a new biopsy showed no evidence of Actinomyces ( $\bullet$ Fig. 2).

Actinomycosis is an uncommon, subacute-to-chronic chronic, suppurative disease that is usually caused by the filamentous, Gram-positive, nonacid-fast, anaerobic-to-microaerophilic bacterium Actinomyces israelii. The pathogen causes characteristic granulomatous inflammatory fibrosis, presenting as a mass lesion $[1,2]$. Left untreated, there is contiguous spread of the suppurative and granulomatous inflammation, and formation of multiple abscesses and sinus tracts, which may discharge "sulfur-like" granules [2]. Rarely, actinomycosis occurs as an intraabdominal infection $[3,4]$. Actinomycosis of the abdomen and pelvis accounts for $20 \%$ of reported cases and pancreatic involvement is even rarer. In the anecdotal cases that are reported, the CT presentation is difficult to distinguish from malignancy. The clinical presentation of abdominal actinomycosis includes low grade fever, weight loss, fatigue, change in bowel habits, vague abdominal discomfort, nausea, vomiting, and sensation of a mass that can mimic neoplastic symptoms. In our case, we were able to make a diagnosis of a granulomatous in-

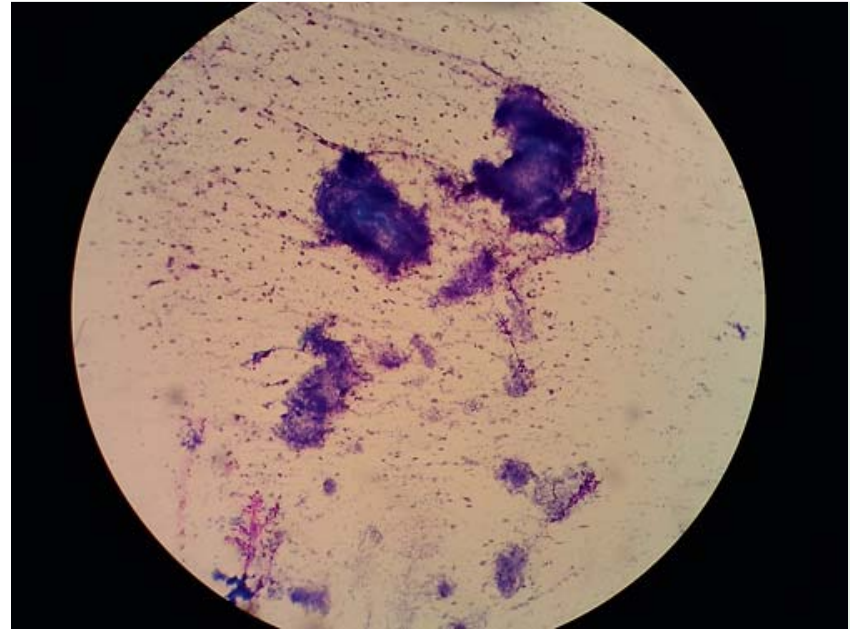

Fig. 1 Hematoxylin and eosin section of a pancreatic biopsy specimen from a 66-year-old man with a 4-month history of abdominal pain poorly responsive to opiate analgesics and with occasional fever. Note the basophilic masses with radiating eosinophilic colonies of Actinomyces.

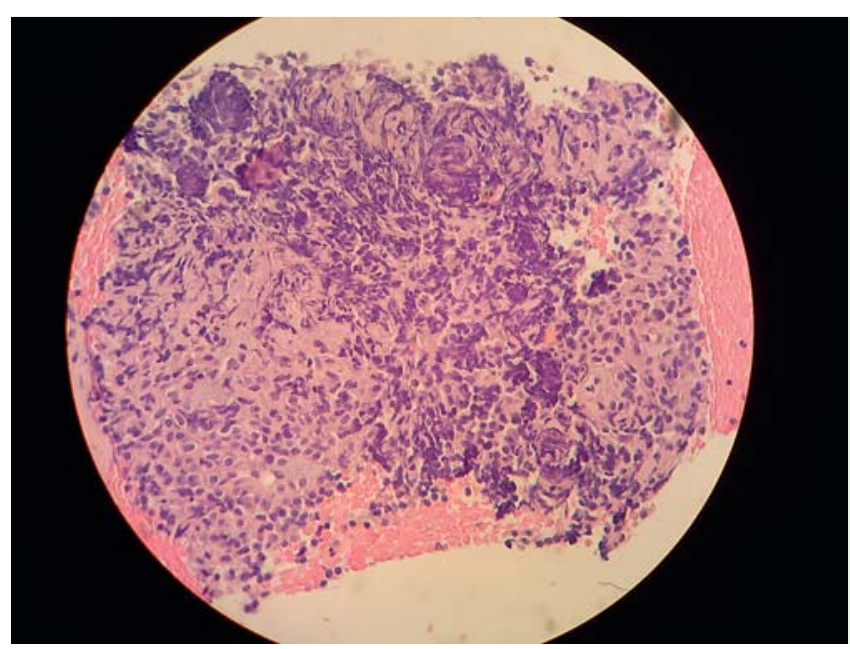

Fig. 2 Hematoxylin and eosin section of the repeat pancreatic biopsy specimen showing lymphocytic infiltrates but no Actinomyces.

fection only after doing a pancreatic biopsy ( Video 1). In most cases of actinomycosis, antimicrobial therapy is the only treatment required, although surgery may be carried out as an adjunctive measure in selected cases.

In conclusion, abdominal actinomycosis is an extremely rare infection that can mimic multiple disease processes and requires accurate diagnosis for successful therapy. Not all pancreatic masses are neoplastic and FNA is essential for diagnosis in these cases.

\section{Video 1}

Fine needle aspiration (FNA) biopsy of the pancreatic mass.
Endoscopy_UCTN_Code_CCL_1AF_2AZ_3AD

Competing interests: None

\section{S. Maestro, R. Trujillo, K. Geneux, M. Garcia, A. Martinez, A. G. Millan, F. Arisqueta}

Hospital Rio Carrion-Digestivo, Palencia, Palencia, Spain 


\section{References}

1 Garner JP, Macdonald M, Kumar PK. Abdominal actinomycosis. Int J Surg 2007; 5: 441 448

2 Sudhakar SS, Ross JJ. Short-term treatment of actinomycosis: two cases and a review. Clin Infect Dis 2004; 38: $444-447$

3 Cintron JR, Del Pino A, Duarte B, Wood D. Abdominal actinomycosis: report of two cases and review of the literature. Dis Colon Rectum 1996; 39: 105-108

4 Milam MR, Schultenover SJ, Crispens $M$ et al. Retroperitoneal fibrosis secondary to actinomycosis with no intrauterine device. Obstet Gynecol 2004; 104: 1134-1136
Bibliography

DOI http://dx.doi.org/

10.1055/s-0032-1310142

Endoscopy 2013; 45: E276-E277

(c) Georg Thieme Verlag KG

Stuttgart · New York

ISSN 0013-726X
Corresponding author

\section{S. Maestro}

Hospital Rio Carrion-Digestivo

c/Donantes de Sangre, s/n

Palencia 34004

Spain

Fax: +97-97-42508

sergipalen@hotmail.com 